\title{
Recovery of protein from urine specimens collected in cotton wool
}

\author{
G C Smith, C M Taylor
}

\begin{abstract}
Cotton wool balls have been used to aid the collection of urine from infants. Concentrations of two urinary proteins, albumin and retinol binding protein, decreased by 40 and $80 \%$ respectively within 15 minutes of contact with the cotton wool. Cotton wool balls should not be used when investigating proteinuria.
\end{abstract}

\section{(Arch Dis Child 1992;67:1486-7)}

Examination and analysis of urine is an important part of the management of a wide variety of medical disorders. Although obtaining urine specimens from older children is a relatively simple procedure, collecting specimens from infants is often less satisfactory. A urine bag may be required and this can be difficult to apply, particularly in girls, with repeated applications liable to cause discomfort. In an attempt to overcome this problem, it has been suggested that urine can be successfully collected in this age group by cotton wool balls held in suitable disposable nappies. ${ }^{12}$ This method of collection has been shown not to interfere with the measurement of a number of urinary constituents (sodium, potassium, nitrogen, creatinine, urea, amino acids), though calcium and phosphorus concentrations are increased. ${ }^{1}$ The validity of this method of collection has not been established for proteins, however, which are commonly investigated in the assessment of renal disease. We therefore looked at the effect of cotton wool on the concentrations of two commonly measured urinary proteins, retinol binding protein and albumin.

\section{Method}

Urine specimens were obtained from normal children and those with glomerular or tubular dysfunction to obtain urine samples with a wide range of retinol binding protein and albumin concentrations. A $20 \mathrm{ml}$ specimen of urine was mixed and then divided into five equal aliquots, four of which were placed on standard cotton wool balls. The urine was then extracted from the cotton wool after 15, 30, 60, and 120 minutes of incubation at room temperature, by compressing the cotton wool ball in a $20 \mathrm{ml}$ syringe. Fourteen specimens were examined with respect to retinol binding protein (concentration range 48-24000 $\mu \mathrm{g} / \mathrm{l}$ ) and albumin (concentration range $3 \cdot 8-72400 \mathrm{mg} / \mathrm{l}$ ). The specimens were then stored at $-20^{\circ} \mathrm{C}$ for up to four weeks before assay. Retinol binding protein was determined using an enzyme linked immunosorbent assay (ELISA) ${ }^{3}$, albumin by a radioimmunoassay, and creatinine by a modified Jaffé reaction.

The results were analysed using a two tailed $t$ test.

\section{Results}

As with previous studies, there was no effect on the determination of creatinine concentration in the urine specimens after contact with cotton wool. The precision of the assays are shown in the table.

There was a significant decrease of $35-40 \%$ $(p<0.05)$ in the albumin concentration, though this was not consistent and a number of specimens showed only a slight loss of albumin. The greatest percentage decreases were seen in urine specimens of lower albumin concentrations

Precision of ELISA for determination of urinary retinol binding protein and of radioimmunoassay for urinary albumin concentrations

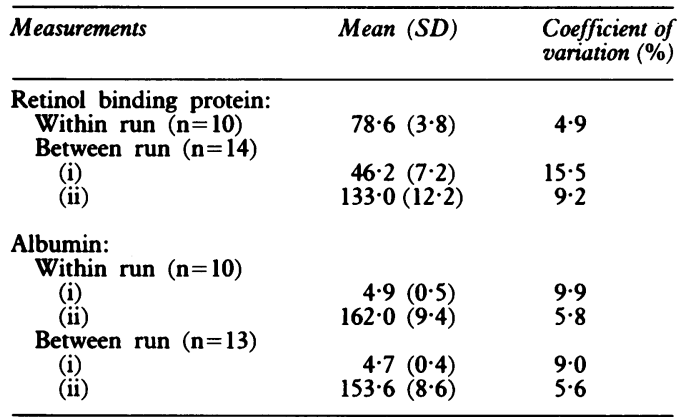

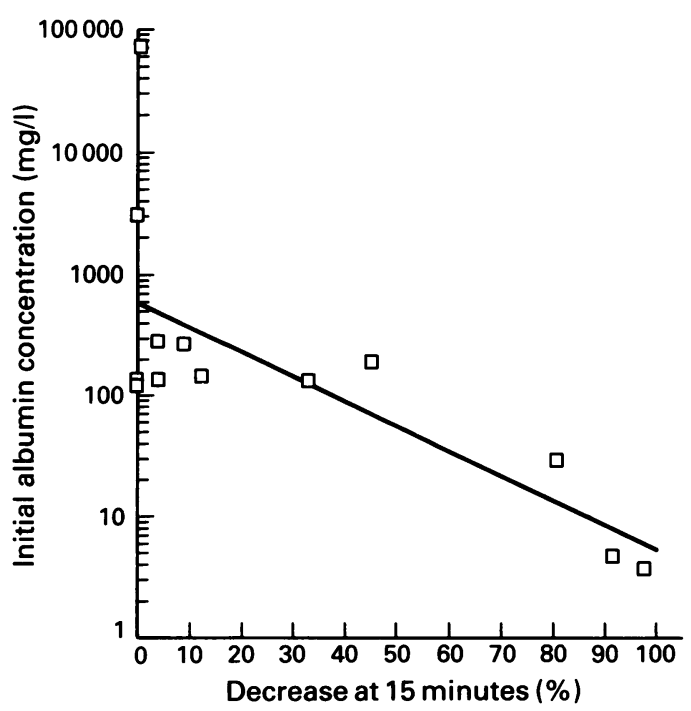

Relationship between decrease in albumin concentration measured and initial concentration of albumin. Pearson's $\omega_{x}=-0.7099 ; p=0 \cdot 004$. 
with an inverse relationship between the percentage decrease at 15 minutes and the initial albumin concentration (figure).

The decrease in retinol binding protein concentration was greater and consistent, amounting to a loss of $80 \%$ of the measurable retinol binding protein $(p<0.001)$. The loss occurred within the first 15 minutes of contact with the cotton wool, was less dependent on the initial retinol binding protein concentration, and did not significantly change over the next 105 minutes.

\section{Discussion}

The difficulties of obtaining urine specimens from infants is well known and attempts to make collection easier are welcomed. The use of cotton wool balls to ease collection of urine for the determination of low molecular mass urinary constituents has been shown to be reliable. We feel, however, that it would be unwise to extend this practice to the collection of urine specimens for the measurement of proteinuria. The fibres used in the manufacture of cotton wool balls appear to absorb at least part of the protein content of the urine and make meaningful measurements impossible.

1 Roberts SB, Lucas A. Measurement of urinary constituents and output using disposable napkins. Arch Dis Child 1985; 60:1021-4.

2 Ahmad T, Vickers D, Campbell S, Coulthard MG, Pedler S. Urine collection from disposable nappies. Lancet 1991;338: 674-6.

3 Topping MD, Forster HW, Dolman C, Luczynska CM, Bernard AM. Measurement of urinary retinol-binding protein by enzyme-linked immunosorbent assay, and its application to detection of tubular proteinuria. Clin Chem 1986;32/10:1863-6. 